\title{
Energy consumption during the building life cycle - influence of investment activities and operations
}

\author{
Dalibor Vytlačil ${ }^{1, *}$ \\ ${ }^{1}$ Czech Technical University in Prague, Faculty of Civil Engineering, Department of Engineering \\ Informatics, Thákurova 7, 16629 Prague, Czech Republic
}

\begin{abstract}
The paper describes the dynamic model of maintenance and investments of a building structure and HVAC systems. The aim of the research is finding the time dependent curve for energy consumption and also the cash flow that depends on the investments to energy saving arrangements and operations. The solution is based on the system dynamics method. The method makes possible to interconnect technical and economic parts of the problem. The main parameter in the model is the energy consumption in the building per floor square meter and year. This parameter is influenced by a deterioration of the building structure and the components of the active elements. The investments realized with the aim to decrease the energy consumption is another influence. The example of the computer simulation of the building parameters during the life cycle is presented in the paper.
\end{abstract}

\section{Introduction}

The prediction of maintenance and investments in the buildings requires more attention. The reason is the amount of financial resources spent for this purpose. The costs of maintenance works are higher than the costs during construction because it is small scale work, it needs a preparation of the site, it influences the operations in the building with possible financial losses [1-2]. The facilities management (FM) deals with described problems. FM is now the important part of the maintenance management domain with the holistic view of problems concerning the buildings.

It is necessary to introduce an objective function for the evaluation of the process quality. In this paper it is annual energy consumption per quadrat meter of the floor space. About $50 \%$ of the cost is spent for energy systems in the buildings. These costs are divided in the ratio 2:1 for manpower and materials.

Another important factor in the problem is the investment activity that can substantially change the output parameters, in this case to reduce energy consumption. The aim of the maintenance is to keep the buildings in the same conditions but investments want to improve the functionality of the building structure. This activity is focused on the passive as

\footnotetext{
* Corresponding author: vytlacil@,fsv.cvut.cz
} 
well as the active elements of the buildings. The model links both factors to one system of interconnected activities.

\section{Description of dynamic model}

The solution is based on system dynamics method. This approach allows us to describe the whole system with all relevant elements, [3-4]. The main part of the model is depicted in Figure 1. The stock parameter is annual energy consumption per square meter that is influenced by increasing flow derived from the deterioration of the building structure and by decreasing flow derived from the investments to the structure.

energy consumption

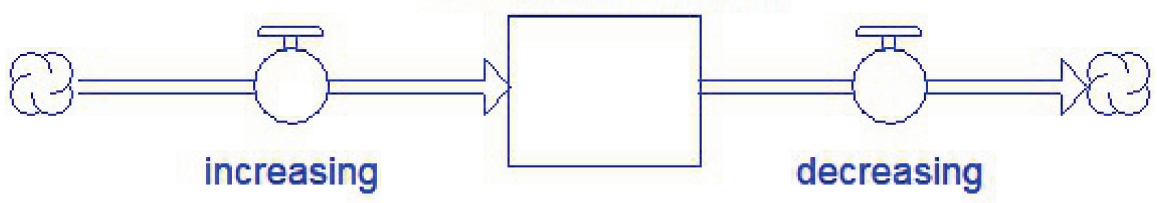

Fig. 1. The main subsystem of the model for the described problem.

\subsection{The structure of the model}

The deterioration depends on costs spent for planned maintenance and ad hoc maintenance (repairs). The decreasing rate depends on the investment costs.

The model includes the financial subsystem that is represented by the cash flow stock. The cash flow element does not include all incomes and outcomes but only relevant items. The income is calculated as saved money from the energy saving arrangements in the building, [5]. The outcome is derived from the maintenance and investment costs, see Figure 2.

\subsection{Input values}

The example was calculated for the family house with floor space $150 \mathrm{~m}^{2}$. The simulation was performed for two levels of planned maintenance $20 \mathrm{CZK} . \mathrm{m}^{-2} \cdot \mathrm{year}^{-1}$ and $40 \mathrm{CZK} . \mathrm{m}^{-}$ ${ }^{2}$.year ${ }^{-1}$. The time period was 40 years. The heat source is a gas boiler. The initial energy price is $2,12 \mathrm{CZK} . \mathrm{kWh}^{-1}$ and can be changed every year by energy price rate. During the life span two investments are considered, in the fifteenth and twenty-fifth years. The investment cost is $2000 \mathrm{CZK} . \mathrm{m}^{-2}$. All input parameters are in Table 1.

Table 1. Input values of the variables.

\begin{tabular}{|c|c|c|}
\hline Initial price of energy & {$\left[\mathrm{CZK} \cdot \mathrm{kWh}^{-1}\right]$} & 2,12 \\
\hline $\begin{array}{c}\text { Initial consumption } \\
\text { of energy }\end{array}$ & {$\left[\mathrm{kWh} \cdot \mathrm{m}^{-2} \cdot \mathrm{year}^{-1}\right]$} & 120 \\
\hline $\begin{array}{c}\text { Annual change of } \\
\text { energy price }\end{array}$ & {$[\%]$} & 3 \\
\hline $\begin{array}{c}\text { Planned maintenance } \\
\text { costs }\end{array}$ & {$\left[\mathrm{CZK} \cdot \mathrm{m}^{-2} \cdot \mathrm{year}^{-1}\right]$} & $20 / 40$ \\
\hline Repair costs & {$\left[\mathrm{CZK} \cdot \mathrm{m}^{-2} \cdot \mathrm{year}^{-1}\right]$} & 20 \\
\hline
\end{tabular}




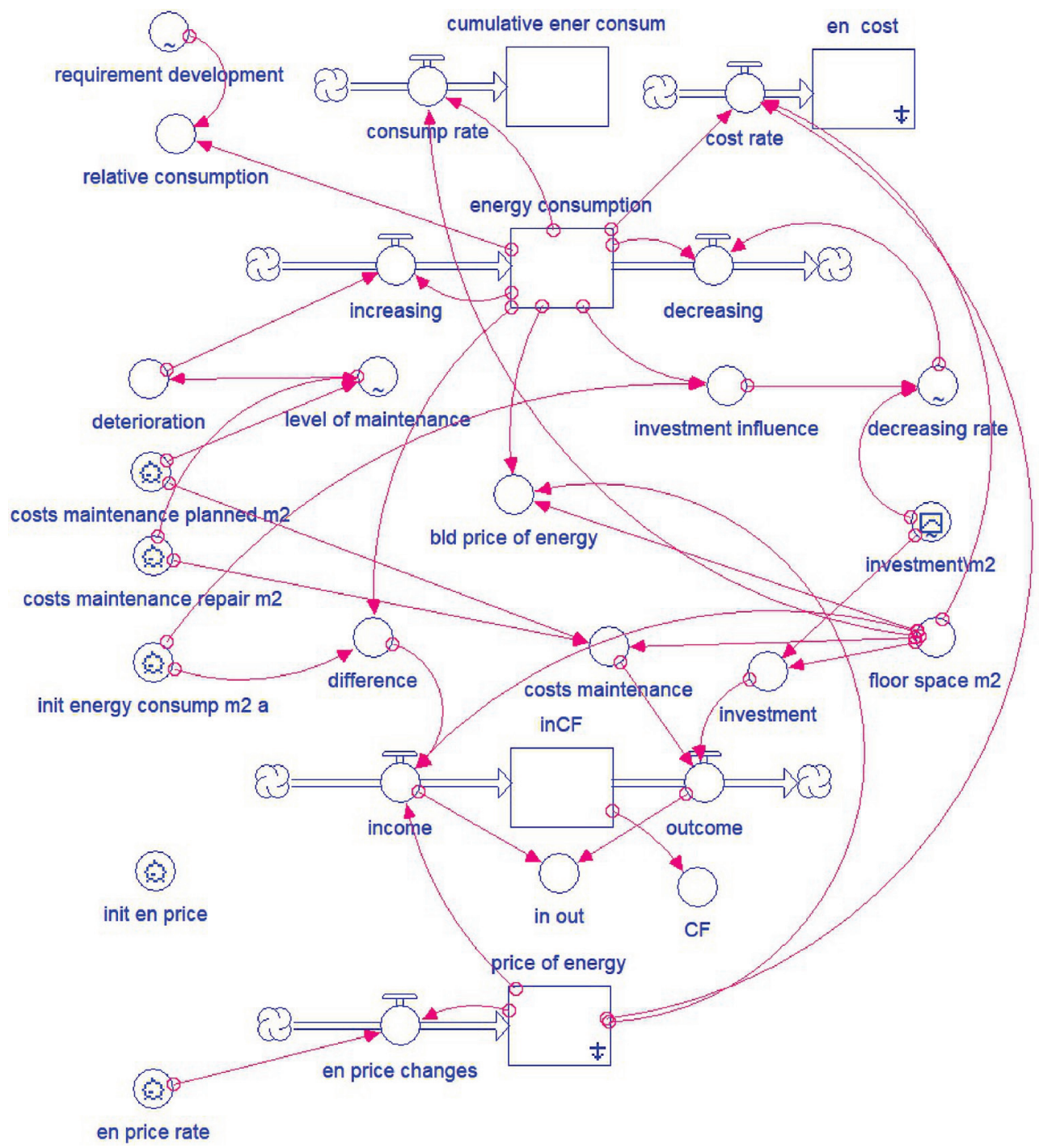

Fig. 2. The dynamic model of the investigated system.

\section{Results}

Output parameters are depicted in the graphs in Figure 3 and Figure 4. The selected parameters are written in Table 2.

To find the influence of certain parameters the sensitivity analysis was performed. The resultant values are drawn in Figure 5. The graph shows the influence of the planned maintenance to the cash flow. It should be compared to the energy consumption. The higher maintenance values improve the energy consumption but the cash flow parameter is worse. It means it is necessary to find the optimal value of the maintenance level. 


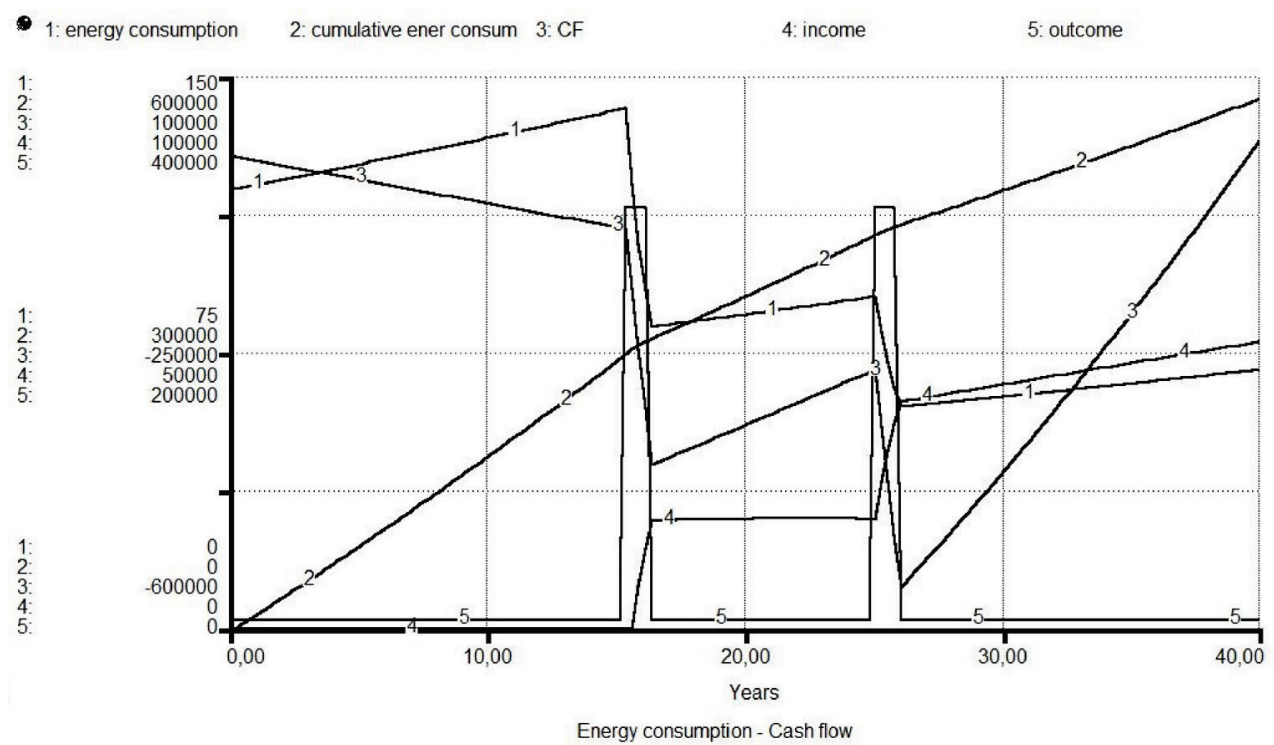

Fig.3. System parameters for planned maintenance $20 \mathrm{CZK} \cdot \mathrm{m}^{-2}$.year ${ }^{-1}$ : 1-energy consumption $\left[\mathrm{kWh} . \mathrm{m}^{-2}\right.$.year $\left.{ }^{-1}\right]$, 2-cumulative energy consumption $[\mathrm{KWh}], 3$-CF [CZK], 2-income [CZK], 3outcome $[\mathrm{CZK}]$.

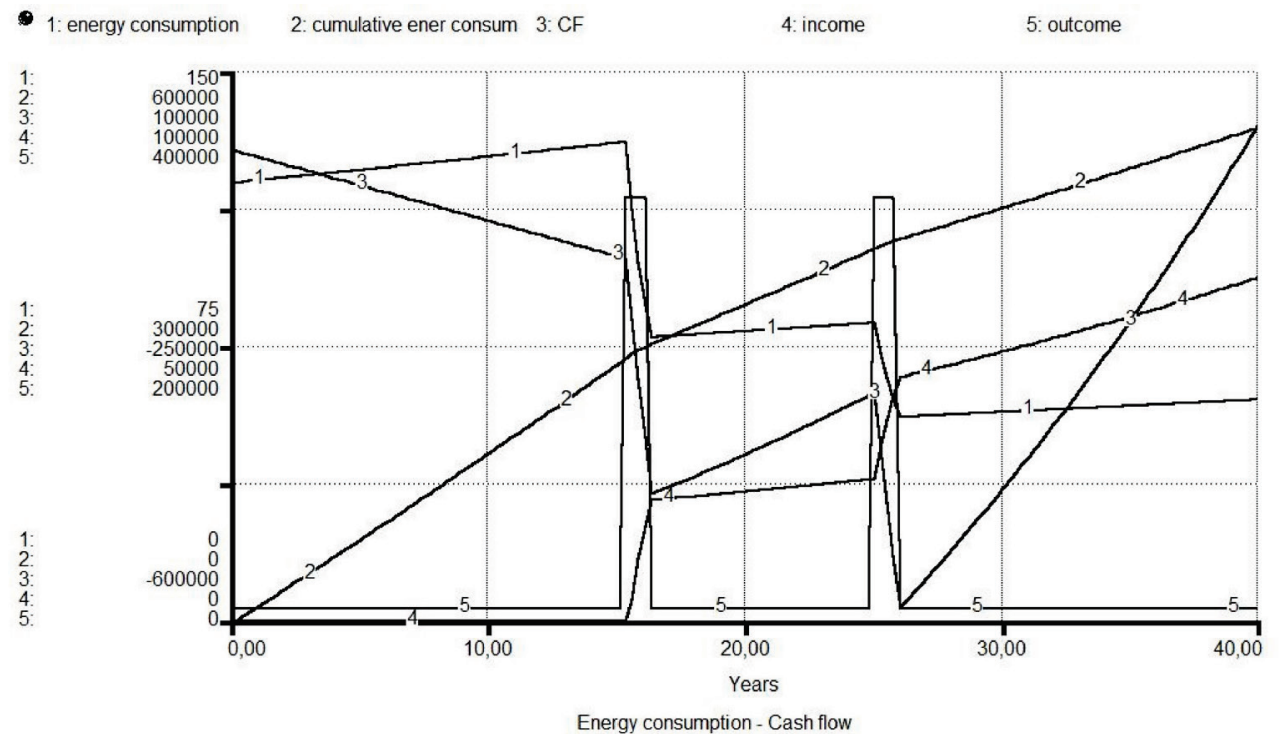

Fig. 4. System parameters for planned maintenance $40 \mathrm{CZK} \cdot \mathrm{m}^{-2}$.year ${ }^{-1}$ : 1-energy consumption $\left[\mathrm{kWh} . \mathrm{m}^{-2}\right.$.year $\left.{ }^{-1}\right]$, 2-cumulative energy consumption $[\mathrm{KWh}], 3$-CF [CZK], 2-income [CZK], 3outcome $[\mathrm{CZK}]$.

Table 2. Output values from the simulation for two cases.

\begin{tabular}{|c|c|c|c|}
\hline Parameter & $\begin{array}{c}\text { Consumption of } \\
\text { energy }\end{array}$ & $\begin{array}{c}\text { Final consumption of } \\
\text { energy }\end{array}$ & Energy costs \\
\hline Case & {$[\mathrm{KWh}]$} & {$\left[\mathrm{kWh} \cdot \mathrm{m}^{-2} \cdot\right.$ year $\left.^{-1}\right]$} & {$[\mathrm{CZK}]$} \\
\hline C 1 & 577356 & 70,5 & 2144640 \\
\hline C 2 & 539607 & 60,5 & 1978895 \\
\hline
\end{tabular}


- $\mathrm{CF}: 1-2-3-4-5-6$ -

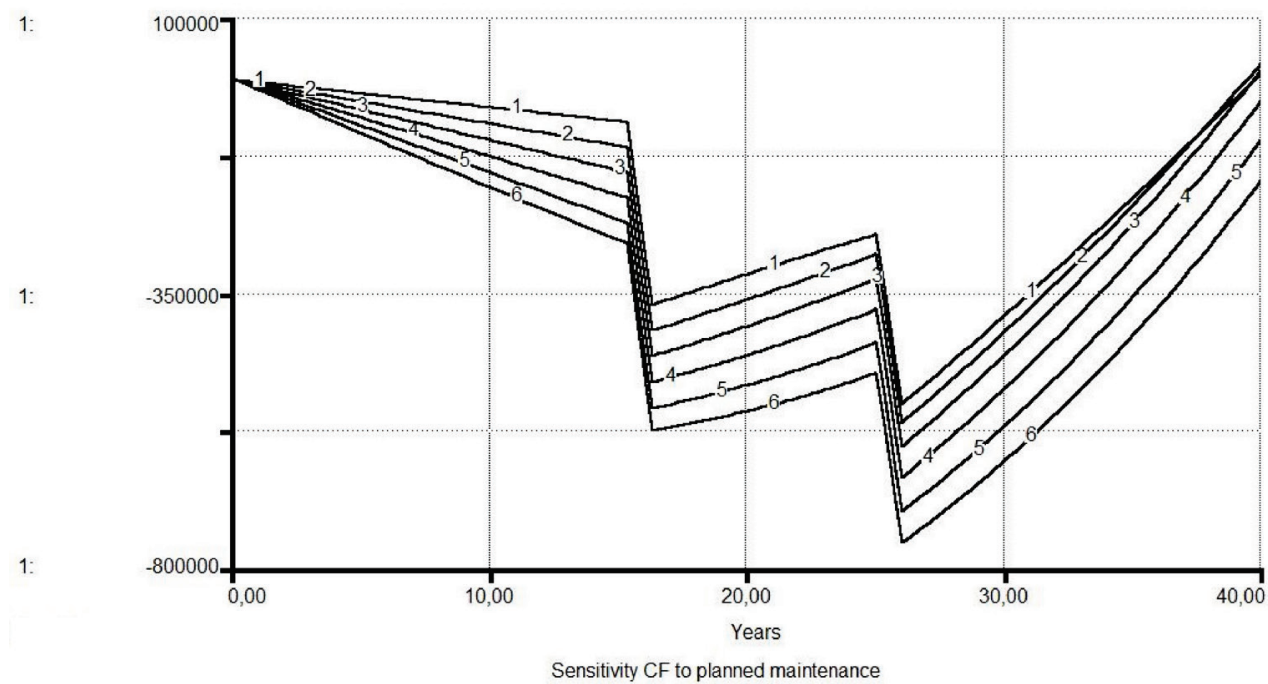

Fig. 5. Sensitivity of cash flow [CZK] to planned maintenance - from 10 to $100 \mathrm{CZK} \cdot \mathrm{m}^{-2}$.year ${ }^{-1}: 1-10$ CZK. ${ }^{-2}$.year ${ }^{-1}$, 2-28 CZK.m ${ }^{-2}$.year ${ }^{-1}$, 3-46 CZK. ${ }^{-2}$.year ${ }^{-1}$, 4-64 CZK.m ${ }^{-2}$.year ${ }^{-1}$, 5-82 CZK.m ${ }^{2}$.year ${ }^{-1}, 6-100 \mathrm{CZK} \cdot \mathrm{m}^{-2}$.year ${ }^{-1}$.

\section{Conclusions}

The model deals with two kinds of parameters. The hard parameters describing the building structure and HVAC systems and soft parameters that is difficult to predict, e.g. changes in the energy price. The variability of the parameters is influenced also by the time period of the simulation - the life span of the building is long compare to other technical systems.

The aim of the research was to describe complex dynamic system with technical and economical parameters influencing the dynamic behavior. The designed model is possible to use for the calculation of the different parameters during the life cycle of the buildings. The model is not the replacement of standard FM programs but it is the tool for strategic decision making.

Another investigation has to be done in long time parameter changes. In this topic, there are the changes in the thermal properties of used materials (due to material moisture, mechanical stress), boiler efficiency, sealing compounds etc. The rate of the changes is influenced by physical properties of the materials but also by the quality of the construction and maintenance works.

Uncountable benefits are the important attribute of the problem. The material and component replacements bring often better functionality and therefore the simple comparison of the building states in certain time is rather difficult. The replacement of the windows is the typical example.

The solution of the problem needs to combine the knowledge from many fields operations management, project management, structure engineering etc. The system dynamics is the good approach that can connect all these knowledge.

This research has been supported by SGS grant SGS17/122/OHK1/2T/11 Dynamic models of changes in building industry investments. 


\section{References}

1. B. Chanter, P. Swallow, Building Maintenance Management (Blackwell Publishing, Oxford, UK, 2007)

2. H. Plat, The Economics of Property Management - The building as a Means of Production (Butterworth Heinemann, Oxford, UK 2001)

3. J. Morecroft, Strategic Modelling and Business Dynamics (Wiley, Chichester, UK, 2008)

4. J.D. Sterman, Business Dynamics: Systems Thinking and Modeling for a Complex World (Irwin/McGraw-Hill, Boston, MA 2000)

5. D. Vytlacil D, Proceedings of the 11th IBPSA Conference 2092-2097, (International Building Performance Simulation Association, Glasgow, 2009) 